\title{
Mapping the road from childhood adversity to personality disorder: The role of unresolved states of mind
}

Short title: Childhood adversity, unresolved states of mind and personality disorder

\begin{abstract}
Childhood adversity has been found to be an important etiological factor in the development of personality disorder (PD) in several studies. However the role of disorganized attachment with unresolved mental states for traumatic experiences requires further investigation. This study explores the relationship between childhood adversities, unresolved states of mind, PD diagnosis and psychiatric distress. 245 adult participants, 124 from a clinical PD group and 121 non-psychiatric controls, were assessed using the Structured Clinical Interview for DSM-IV, the Cassel Baseline Questionnaire, the Symptom Checklist-90-R and the Adult Attachment Interview, in order to ascertain presence of PD, childhood adversity, level of psychiatric distress and unresolved states of mind. Within the overall unresolved (U-overall) attachment category a distinction was made between Unresolved for abuse (U-abuse) and Unresolved for loss (U-loss). The results indicated that childhood adversity was significantly associated with unresolved states of mind, as well as with overall PD diagnosis, paranoid PD, borderline PD, avoidant PD, and psychiatric distress. Mediation analyses confirmed that U-overall and U-loss were significant mediators between childhood adversity and PD diagnoses, but surprisingly U-abuse was not a significant mediator. The strength, limitations and clinical implications of the findings are discussed
\end{abstract} Keywords: Attachment, childhood adversity, personality disorder, psychiatric distress, unresolved states of mind 
Paper classification: Research paper

Sponsor: The Laurence Misener Charitable Trust provided a grant 


\section{INTRODUCTION}

Personality Disorder (PD) is considered a pervasive form of psychopathology and represents a serious public health problem. The prevalence of PD is estimated at $10 \%$ in the general population (Torgersen, 2005), but the percentage is much higher in clinical settings (Tyrer, Reed, \& Crawford, 2015). Individuals with PD diagnoses usually exhibit a heightened risk for hospitalization (Bender et al., 2001), self-harming behaviors and suicidality (Tyrer, 2009), delinquency (Johnson et al., 2000), and occupational and interpersonal difficulties (Skodol et al., 2002).

Although the role of genetic factors and neurobiological correlates to both attachment and trauma has shown to be relevant in the etiology of PD (Gabbard, 2005; McCrory, De Brito, \& Viding, 2012), over the last decades, a large body of literature has highlighted the link between childhood adversity and PD, especially borderline PD (Soloff, Lynch, \& Kelly, 2002; Zanarini, 2000). Early studies on childhood traumatic events and the process of traumatization have shown that they have a pervasive impact on current functioning and personality development, with a higher risk of later development of chronic psychological and behavioral difficulties, such as disturbance in affect regulation, impulse control, reality testing, interpersonal relationship and self-integration (Carr, Martins, Stingel, Lemgruber, \& Juruena, 2013; Chen et al., 2010). Neglect and abuse have been found to be major risk factors in the etiology of borderline PD (Crawford, Cohen, Chen, Anglin, \& Ehrensaft, 2009; Gunderson et al., 2000).

Due to the importance of the early environment to children's psychological and social development (Cicchetti, Cummings, Greenberg, \& Marvin, 1990; Fonagy et al., 2010), 
attachment theory has acquired a central place among current conceptualizations of trauma-related problems and their long term clinical implications (Hesse, 2016; Meyer, Pilkonis, Proietti, Heape, \& Egan, 2001). The impact of early adversity on the capacity to develop secure attachment on parental figures has been investigated in several studies, which have shown that early adversities have a disrupting impact on internal representations, causing disorganized attachment, which in turn predicts later development of PD (Barone, 2003; Fonagy et al., 1996; Steele, 2008). Disorganized attachment has been found to be consistently associated with a previous history of neglect and physical and/or sexual abuse (Cicchetti et al., 1990) and is a significant risk factor for later psychopathology (Lyons-Ruth, 1996). Longitudinal investigations have confirmed the relationship between infant disorganized attachment and later psychopathology (Lyons-Ruth, 1996), including dissociative symptoms (Carlson, 1998). A specific pathway linking disorganized attachment representations in infancy to adult Unresolved/disorganized (U/d) states of mind has been investigated (Sroufe, Egeland, Carlson, \& Collins, 2005). Thus, disorganization of attachment can be considered a vulnerability factor for later psychological disturbance.

The U/d category of attachment, which corresponds to the disorganised-disoriented attachment of the infant, was added to the original organized categories (Secure, Preoccupied and Dismissive) to fill a gap in the classification of AAI transcripts, pointing to a possible inadequacy of the three organized categories (Main \& Solomon, 1990). It was formulated that $\mathrm{U} / \mathrm{d}$ states of mind are closely linked to early experiences of loss and trauma (Hesse \& Main, 2000). The U/d describes a fragmentation of awareness, lack of integration and a dissociative state of mind as a result of the impact of early experiences of loss or abuse on the state of mind and the quality of attachment to primary figures (Hesse, 
2016; Main \& Hesse, 1990). Lack of resolution is inferred when people show confused discourse when talking about traumatic events. $U / d$ states of mind is coded separately from the other categories, which results in a subject's narrative being assigned to one of the three organized categories and resolved or unresolved for abuse or loss (Hesse, 2016). High rates of $\mathrm{U} / \mathrm{d}$ attachment have been consistently found in cohorts with PD diagnosis, especially borderline PD (Barone, Fossati, \& Guiducci, 2011; Dozier, Stowall-McColough, \& Albus, 2008; Fonagy et al., 1996). Some researchers have studied the nature of the $U / d$, suggesting that it may represent a dissociative state (Hesse \& van ljzendoorn, 1999; Liotti, 1992). Nevertheless, $\mathrm{U} / \mathrm{d}$ represent a complex construct and there is some ambiguity about its nature and aetiology (Duschinsky, 2015; Hughes, Turton, Hopper, McGauley, \& Fonagy, 2004; Lyons-Ruth, Yellin, Melnick, \& Atwood, 2003).

Although the key role of environmental early experiences in the etiology of PD has been widely illustrated, we know that not everyone who suffered childhood adversities develops personality disturbance in later life. The likely role of mediating and/or moderating factors, other than childhood adversity, that influence and shape the pathway between early trauma and the development of PD requires further investigation.

The current study aims to broaden the existing literature on PD by investigating the relationship between childhood adversity (loss and abuse) and PD diagnosis, and exploring the possible role of unresolved/disorganized states of mind as potential significant mediators between childhood adversity and PD. The hypotheses tested are: (1) sexual abuse, physical abuse and loss are significantly associated with PD and current level of 
psychiatric distress; and (2) the unresolved/disorganized states of mind mediate the link between past traumatic experiences and PD diagnosis.

\section{METHOD}

This study was based at the Cassel Hospital, Richmond, UK, a specialist personality disorder service, which provides assessment and treatment for adults and young people with severe and complex PDs. The majority of patients admitted for treatment at the Cassel suffer from chronic PDs (two-thirds have a borderline PD) and have been unresponsive to other traditional psychiatric approaches (Chiesa, 2000).

\section{Study sample}

This cross-sectional controlled study compares an adult sample with PD ( $N=124)$ treated at the Cassel Hospital, London, UK and a non-psychiatric control group without any PD diagnosis ( $\mathrm{N}=121)$ treated for medical and surgical conditions at University College London Hospitals. Inclusion criteria were age 18-53 and, for the psychiatric sample, meeting the diagnostic criteria for at least one PD, and for the control group absence of any PD diagnosis. Exclusion criteria included a diagnosis of schizophrenia or evidence of organic brain disorder. The psychiatric patients were matched on age and gender with the control participants. After identifying potential suitable patients in both centers, they were met by a member of the research team to provide information about the content and scope of the study, to answer any questions the patient might have and to obtain written consent to participate in the study. Confidentiality and anonymity were ensured. Ethical approval was granted by the Research Ethics Committee of the West London Mental Health Trust. 


\section{Measures}

Childhood experiences of abuse and loss were collected through the Cassel Baseline Questionnaire, a questionnaire based on a structured interview with operationalized definitions (Chiesa \& Fonagy, 2000) eliciting experiences of loss, sexual abuse and physical abuse as three separate variables. Early loss was defined as significant periods of separation from a primary caregiver or important relative during the first 10 years of life, due to death, hospitalization, adoption, foster home, divorce, etc. Sexual abuse was elicited from the subject's report of sexual interference by an adult or forced sexual assault before the age of 14. Reports of maltreatment by caregivers, such as repeated slapping, extreme verbal abuse, beating, kicking, episodes of continuous physical humiliation, defined presence of physical abuse. These definitions were modelled on the work of Bifulco (1994) for the retrospective elicitation of childhood experiences of care and abuse. The presence of adversities was rated by the interviewer on a 5 -point scale of severity $(0=a b s e n t, 1=$ mild, 2=moderate, $3=$ severe, $4=$ =very severe) following operational definitions with anchor points. Subsequently, we dichotomized the trauma variables into presence or absence of adversity by recoding absent and mild into absent and moderate, severe and very severe into present. The Structured Clinical Interview for DSM-IV-II (SCID-II) (First, Spitzer, Gibbon, \& Williams, 1997) is a semi-structured diagnostic interview for assessing the presence/absence of the ten DSM-IV (American Psychiatric Association, 1995) axis-II PDs. The SCID-II has been found to be a sensitive and specific interview, with a low rate of false negatives (Ekselius, Lindstrom, von Knorring, Bodlund, \& Kullgren, 1994; Jacobsberg, Perry, \& Frances, 1995). The Symptom Checklist-90-R (SCL-90-R) (Derogatis, 1983) is a well-established measure of subjective severity of general psychiatric distress. The SCL-90-R is a self-report clinical rating 
scale, which yields a General Severity Index (GSI), computed by averaging all the scores, as an overall measure of severity of psychiatric symptoms

The Adult Attachment Interview (AAI) (George, Kaplan, \& Main, 1985) is considered the best measure to rate adult attachment (Hesse, 2008). This semi-structured interview assesses the organization of adult's current state of mind with respect to attachment and resolution of traumatic past experiences. The AAI enquires about the quality of childhood experiences with the primary caregiver and the impact of these experiences, including questions about experiences of loss and trauma. All AAls were audio-recorded, transcribed and scored according to the standard AAI classification system (Main, Hesse, \& Goldwyn, 2008) by trained reliable raters, who were blind to any clinical information regarding the patients and to the study design and aims. A four-way classification system was used which included the secure, dismissing, preoccupied and unresolved/disorganized $(U / d)$ attachment categories. In addition, within the $\mathrm{U} / \mathrm{d}$ category a distinction was made between Unresolved for abuse and Unresolved for loss. A score was given for evidence of unresolved discourse on a 1-9 point scale, with 5 or greater rated as unresolved. An overall unresolved score $(U$ overall), and separate scores for unresolved discourse relating to loss (U-loss) and abuse (Uabuse) were obtained (Main \& Goldwyn, 1991) (Hughes et al., 2004). Determination of U/d relies on expert examination of how participants discuss the traumatic experience, and is assigned when respondents show signs of disorientation and disorganization during the narrative of potentially traumatic events. Signs of $U / d$ includes lapses in the monitoring of discourse such as disorientation to space and time, confused speech, confusion and disbelief about abuse or death, extreme absorption, protracted silences, incomplete sentences, abrupt changes of argument, or intrusion of memories of loss or trauma that randomly appear throughout the interview (Hesse, 2008). 


\section{Statistical analysis}

Chi-squared tests for categorical variables and independent samples t-tests for continuous variables were used to test differences between the PD and non-PD samples in demographics, childhood adversity (loss, sexual abuse, and physical abuse), self-reported severity of psychiatric symptoms (GSI) and Main taxonomic attachment categories. The first analyses consisted of examining associations between adversities and outcome variables (diagnoses of PD and GSI) and between the different adversities and attachment classifications. Then, separate logistic regressions analyses were carried out to test the strength of the association between childhood adversity (experiences of sexual abuse, physical abuse and loss) and overall PD and selected PD diagnoses. To assess which adversity variables were most strongly associated with the severity of psychiatric symptoms (GSI) and the severity of PD expressed as number of PD diagnoses met in the SCID-II, multiple linear regression analyses, with $95 \%$ bias corrected confidence intervals $(\mathrm{Cl})$ and significance values of the model's parameters based on 1000 bootstrap samples, were conducted. Finally, in order to test the hypothesis that $\mathrm{U} / \mathrm{d}$ attachment mediates the relationships between childhood adversities and current PD diagnosis, we carried out separate mediation analyses with abuse (a combination of sexual and physical abuse) and loss as independent variables, PD as outcome variable and U-overall, U-abuse and U-loss as potential mediators, using SPSS PROCESS. Bootstrapping procedures allows generating random resampling data with replacement from the original sample; for this study, data were resampled 10,000 times. According to Preacher and Hayes's guidelines (Preacher \& Hayes, 2008), significant indirect effects was assumed when the $95 \%$ bias corrected confidence intervals ( $\mathrm{Cls}$ ) for unstandardized path coefficients did not contain zero within 
range estimates, considering an alpha level of 0.05 (Hayes \& Matthes, 2009; MacKinnon, Lockwood, Hoffman, West, \& Sheets, 2002). Since this approach does not assume normally distributed indirect effects or sampling statistics, it is considered more powerful and accurate than other approaches for testing mediation.

All statistical analyses were performed using SPSS for window v 22.0.

\section{RESULTS}

Participants in the study sample were on average 32 years-old, mostly female (68.6\%). The PD and non-PD samples were similar in age and gender (table 1). Over half of the sample $(n=124,50.6 \%)$ met criteria for at least one PD: the most represented PD diagnoses were borderline ( $n=68,27.8 \%)$, avoidant $(n=67,27.3 \%)$ and paranoid $(n=50,20.4 \%)$. Within the PD sample, the average number of PD diagnoses each patient met criteria for was 3.97 (SD=2.33, Median 3.50). In the overall sample, 85 (34.7\%) participants reported experiences of early loss, $62(25.3 \%)$ of physical abuse and $68(27.7 \%)$ of sexual abuse. With regard to adult attachment, using a 4-way-AAI classification, 82 (33.5\%) participants were classified as secure, $52(21.2 \%)$ as dismissing, $31(12.7 \%)$ as preoccupied and $80(32.7 \%)$ as unresolved/disorganized.

\section{Childhood adversity, PD and unresolved attachment in adulthood}

As expected, the two samples were significantly different in early adversities and psychiatric severity variables (table1). Compared to the non-PD sample, the PD sample reported significantly higher frequency of sexual abuse, physical abuse and loss. The difference in self-reported severity of psychiatric symptoms, as measured by the GSI, was also significant. 
With regard to attachment status, using a 4-way-AAl classification, significant differences were found between the two samples in the secure and unresolved/disorganized categories (Table 1). While only $12(14.6 \%)$ were coded as secure in the PD-sample compared to 70 (85.4\%) in the non-PD sample. 69 (86.3\%) were coded as unresolved/disorganized in the PD sample compared to only $11(13.8 \%)$ in the control sample. In particular, unresolved for abuse (PD $n=43,34.7 \%$ v non-PD $n=9,17.3 \%$ ) and unresolved for loss (PD $n=34,27 \%$ vonPD $n=2,1.7 \%$ ) were also significantly different in the two groups. However, there were no significant differences in the two groups in the dismissing and preoccupied categories of organized insecure attachment.

Further, it was found that $90.2 \%(\mathrm{~N}=55)$ of participants within the $\mathrm{U} / \mathrm{d}$ sub-group had a history of childhood adversity (loss or/and abuse) and that $61.1 \%(\mathrm{~N}=55)$ of participants who reported experience of trauma were coded as $\mathrm{U} / \mathrm{d}$. Specifically, $61.1 \%(\mathrm{~N}=23)$ of those who had reported experiences of early loss were coded as $\mathrm{U} / \mathrm{d}$ for loss, and $87.0 \%$ of participants with a history of abuse were rated as $\mathrm{U} / \mathrm{d}$ for abuse.

Correlational analyses for the whole study sample showed that current diagnosis of PD was significantly associated with experiences of loss (Phi=0.48, $p<0.0001)$, sexual abuse (Phi=0.50, $p<0.0001)$ and physical abuse $(P h i=0.43, p<0.0001)$. Self-reported severity of psychiatric symptoms (GSI) and average number of PD diagnoses were also found to be significantly associated with experiences of loss $\left(r_{s}=0.32, p<0.0001 ; r_{s}=0.43, p<0.0001\right.$, respectively), sexual abuse $\left(r_{s}=0.47, \mathrm{p}<0.0001 ; 0.54, \mathrm{p}<0.0001\right.$, respectively) and physical abuse $\left(r_{s}=0.44, \mathrm{p}<0.0001 ; 0.45, \mathrm{p}<0.0001\right.$, respectively). 
With regards to 4-way attachment classification, while insecure-organized classifications (dismissing and preoccupied categories) were not found to be significantly correlated to adversity variables, the $\mathrm{U} / \mathrm{d}$ category was significantly associated with early experiences of loss (phi=0.33, $p<0.0001$ ), sexual abuse ( $p h i=0.46, p<0.0001$ ) and physical abuse (phi=0.38, $p<0.0001)$. In addition, $U / d$ showed a relatively strong association with current PD diagnosis (phi=0.50, $p<0.0001$ ), as well as severity variables including severity of psychiatric symptoms (GSI) $\left(r_{s}=0.45, \mathrm{p}<0.0001\right)$ and number of PDs $\left(r_{s}=0.51, \mathrm{p}<0.0001\right)$.

In order to ascertain which past experiences of adversity were more strongly associated with PD diagnoses, separate logistic regressions with experience of loss, sexual abuse and physical abuse as independent variables and current overall PD diagnosis and the most frequent specific PD diagnoses (paranoid, borderline and avoidant) as outcome variable, were carried out. The results are presented in Table 2.

With regards to overall diagnosis of $P D$, the fit of the model was significant $\left(\chi^{2}(3)=128.32\right.$, $p<0.0001$ ), with Nagelkerke's $R^{2}=.54$, indicating a moderately strong relationship between predictors and outcome. It was found that the experience of sexual abuse made the most significant contribution to the association with a diagnosis of $P D s(B=2.44, S E=0.50$, $p<0.0001)$, paranoid $P D(B=1.77, S E=0.38, p<0.0001)$, borderline $P D(B=1.33, S E=0.34$, $p<0.0001)$ and avoidant $P D(B=1.53, S E=0.35, p<0.0001)$. Odds ratio calculation showed that patients with past experience of sexual abuse have an 11.44-fold likelihood of meeting a PD diagnosis compared with participants without previous experience of sexual abuse. 
It was also tested whether the adversity variables were significantly associated with severity of psychopathology as measured by the GSI and the number of PDs met in the samples. Two multiple linear regression analyses (table 3 ) revealed that all three adversity variables were significantly correlated with both number of $\operatorname{PD}\left(F_{(3,241)}=47,52, p<0.0001\right.$, with $R^{2}=0.37$ and Adjusted $\left.R^{2}=0.36\right)$ and severity of psychiatric distress $\left(F_{(3,241)}=39.23, p<0.0001\right.$, with $R^{2}=0.33$ and Adjusted $\mathrm{R}^{2}=0.32$ ). Again, sexual abuse was revealed to be the stronger factor associated with both severity of psychiatric symptoms (Beta $=0.032, p>0.001$ ) and number of PD (Beta=0.35, p>0.001).

\section{Mediation analyses}

Because regression analyses confirmed the relationship of past traumatic experiences with both unresolved state of mind and current diagnosis of PD, we tested the role of the overall unresolved state of mind (U-overall) as a potential mediator of the relationship between childhood adversity (including experiences of loss, sexual and/or physical abuse) and current PD diagnosis, using PROCESS in SPSS with bootstrapping procedures.

The mediation model supported the hypothesized mediation effect by U-overall on the relationship between childhood adversity and current PD diagnosis (Figure1). The mean indirect effect from the bootstrap analysis was positive and significant ( $a * b=0.45, S E=0.18$ ) with the $95 \% \mathrm{Cl}$ did not include zero $[0.15,0.88]$. The direct effect $c^{\prime}=1.74(\mathrm{SE}=0.26)$ remained significant $(p<0.0001)$, suggesting that $U$-overall may be only one of the factors involved in mediating the effect of adversity on personality development. 
In order to test whether there were any differences in the mediation path when considering experience of loss and abuse separately, two more mediation analyses were carried out: one with unresolved scale of mind for loss (U-loss) as mediator variable and experience of loss as independent variable, and another with unresolved state of mind for abuse (Uabuse) as a mediator and experience of abuse (sexual and physical abuse) as independent variable. Both mediation analyses used current PD diagnosis as the target dependent variable. The mediation model testing the possible mediation effect by $U$-loss on the relationship between childhood experience of loss and current PD diagnosis was supported (figure 2). There was a significant indirect effect from the bootstrap analysis $(a * b=1.20$, $\mathrm{SE}=2.00$ ) with $95 \%$ confidence interval not including zero $[0.51,7.53]$. The direct effect $c^{\prime}=2.04(S E=0.37)$ was also highly significant $(p<0.0001)$, indicating that the effect of loss on PD remained significant also when the effect of the mediator was taken into account. Again, this was a complementary mediation which may suggest that together with U-loss there may be other factors involved in mediating the effect of loss on PD. Surprisingly, the mediation effect by $U$-abuse on the relationship between childhood experience of abuse (both sexual and physical abuse) and current PD diagnosis was not supported. While the direct effect $c^{\prime}=2.47(S E=0.39)$ was significant $(p<0.0001)$, the mean indirect effect from the bootstrap analysis was not significant $(a * b=0.34, \mathrm{SE}=0.43), 95 \% \mathrm{Cl}$ including $0[-0.27,1.05]$. Although the mediation effect of $U$-abuse was not supported, the presence of direct effect may point to the likelihood of an omitted mediator.

In conclusion, the findings show that in this sample, while $\mathrm{U}$-abuse did not have a mediating effect on development of PD, U-overall and U-loss partially mediated the impact of trauma on having a PD diagnosis. Thus, differences in U-overall and U-loss accounted for the 
likelihood of PD diagnosis and mediated the impact of early traumatic experiences. However, these mediational analyses cannot confirm causality because of the crosssectional nature of the data (Kraemer, Kiernan, Essex, \& Kupfer, 2008) and the presence of a significant direct effect may also suggest the presence of other possible mediators.

\section{DISCUSSION}

This study examined the relationships between childhood adversity, unresolved/disorganized attachment and a diagnosis of PD in later life. In line with previous findings, it was confirmed that childhood experiences of loss and/or abuse were significantly associated with later onset of PD and higher level of psychiatric distress (Brown, Cohen, Johnson, \& Smailes, 1999; Crawford et al., 2009; Riggs et al., 2007; Zanarini, 2000). These findings suggest that early adversity may play an important in the development of PD and clinical severity of presentation in adulthood. In contrast to the insecure/organized categories of attachment, the unresolved/disorganized category showed a significant association with childhood adversity, PD diagnoses and severity variables, which indicates that a lack of resolution of these experiences may be an important factor in shaping the developmental pathway in the direction of long-term negative effects that continue into adulthood (Bakermans-Kranenburg \& van IJzendoorn, 2009; Barone, 2003; Sroufe, 2005). These findings are consistent with previous research that highlights that $U / d$ attachment category tends to be overrepresented in clinical populations, including PD (Diamond et al., 2014; Holmes, 2004; Hughes et al., 2004).

Our results also confirmed the hypothesis that the association between childhood experiences of trauma and current PD diagnosis would be, at least partly, mediated by the 
degree to which participants resolved early traumatic experiences. The significant mediation model linking childhood adversity, overall unresolved scale of mind (U-overall) as a mediator, and current PD diagnosis may indicate that the association between childhood adversity and adult PD was partially explained by difficulties in elaborating earlier traumatic experiences and lends some support the theoretical framework that unresolved state of mind is one mechanism through which childhood trauma may increase the risk for PD. However, since both indirect (the mediation effect) and direct effects were significant, the presence of a complementary or partial mediation (Baron \& Kenny, 1986) suggests the likelihood of other mediators not included in this study (Dakanalis et al., 2014).

Separate mediation analyses for loss and abuse yielded mixed results. The mediation model linking childhood experience of loss as a predictor, U-loss as a mediator, and current PD as outcome variable was a significant model. U-loss partially mediated the relationship between childhood loss and current PD diagnosis suggesting that unresolved experiences of loss is a factor that may enhance the risk for PD in later life. However, since there was common variance between adversity and PD even after U-loss was controlled for, there may be factors other than loss implicated in mediating the effect of early loss on PD development. Surprisingly, the mediation model linking childhood abuse as independent variable, U-abuse as a mediator, and current PD diagnosis as outcome was not significant. Although the direct effect of childhood abuse on current PD was significant, differences in U-abuse did not mediate the impact of childhood abuse. Apart from suggesting the likelihood of other possible unknown mediators, this negative finding may be accounted for by the under-reporting of abusive experiences, particularly sexual abuse in the scoring of the AAI (Bailey, Moran, \& Pederson, 2007). In addition, since the AAI was originally 
developed for low-risk samples, it may not explore in sufficient depth the occurrence of potentially traumatic experiences other than death, therefore raising questions about the reliable measurement of unresolved/disorganized states of mind (Lyons-Ruth et al., 2003). Loss experiences are more easily recognized, while there is often ambiguity in the correct individuation of abuse or the extent of it. Interestingly, results from a number of studies have pointed to a possible wider etiological basis for the $U / d$ category. For example, Hughes and colleagues (2004) suggested that factors other than childhood adversity such as adult traumas, may be associated with the $\mathrm{U} / \mathrm{d}$ category. Lyons-Ruth and colleagues found that unresolved states of mind were unrelated to the severity of childhood trauma and that maternal $\mathrm{U} / \mathrm{d}$ did not mediate the effect between early parental loss and disorganized attachment in the offspring (Lyons-Ruth et al., 2003). Therefore, it appears that the meaning and underlying features of the concept of $U / d$ attachment requires further clarifications (Duschinsky, 2015; Hughes et al., 2004; Lyons-Ruth et al., 2003). Hence, the AAI U/d category is a complex construct that needs to be interpreted with care and more studies are needed to explore this further.

The finding that the direct effect of adversity on PD, after unresolved state of mind was controlled for, continued to be significant in the mediation analyses leads to a number of considerations. First, the $\mathrm{U} / \mathrm{d}$ category may not fully capture the constructs underlying $\mathrm{U} / \mathrm{d}$ states of mind, especially with regard to abuse (Hughes et al., 2004; Lyons-Ruth et al., 2003). Second, the AAI-based $\mathrm{U} / \mathrm{d}$ state of mind may not be the only mediating mechanism linking childhood trauma to PD, and other factors need to be taken into account, including reflective functioning (Chiesa \& Fonagy, 2014), emotional regulation (Linehan \& Heard, 1993), and a combination of environmental and neuro-biological factors (Braun \& Bock, 
2011; Fonagy, Luyten, \& Strathearn, 2011; Schore, 2009; Van Ijzendoorn \& Bakermans-

Kranenburg, 2006). This indicates that there may be several independent pathways linking early adversity to PD diagnosis.

A number of limitations in this study need to be borne in mind when interpreting the results. First, since the data used were cross-sectional without any direct manipulation of variables, no solid conclusions can be drawn about causality, prediction or time of onset of PD. This model can test only whether the hypothesized cause and effect co-occur and, while allowing the identification of statistical mediation, it cannot provide definitive evidence of causal mediation. In cross-sectional studies it is more difficult to disentangle the mediating from the independent variable, making the identification of the mediator somewhat arbitrary. We also need to take into consideration that current levels of distress may have an influence on the sharpness of recall of past experiences, which may be reconstructed as more traumatic than it was originally the case by participants under the influence of current levels of severity of psychopathology. This effect may lead to a degree of confounding in the association of childhood trauma and PD. Hence, prospective longitudinal studies are needed to make claims about causality, prediction and temporal onset of PD and to investigate whether PD features and unresolved/disorganized state of mind have reciprocal effects. Secondly, since the presence of childhood adversity relied on retrospective self-report accounts, the potential effect of memory bias on individuals' accounts of childhood experiences needs to be taken into consideration. There can be wide individual and group variations in what individuals consider being abused and which experiences they are willing to discuss. However, as a safeguard to validity, participants in this study were asked about 
the occurrence of specific past traumatic experiences through a structured interview, rather than relying only on a self-rated questionnaire.

Thirdly, our definition of loss as one of the adversity variables, which is to some degree an indicator of neglect as an inevitable consequence of prolonged or permanent separation from a primary caregiver, did not specifically measure the dimension of emotional maltreatment and neglect, which recent studies have suggested being significant risk factors for development of PD (Chesin, Fertuck, Goodman, Lichenstein, \& Stanley, 2015). Although it would have been desirable to include a measure of neglect and emotional abuse, the study focus was on the evaluation of the role played by unresolved states of mind for loss and abuse.

The adequate power of the study sample that included matched clinical and non-clinical participants was one of the strength of this study, as studies investigating the impact of childhood trauma have often included clinical samples only (Riggs et al., 2007; StovallMcClough \& Cloitre, 2006). The clinical PD-sample was recruited from a public state-funded specialist service, which is likely to be representative of severe PD in public mental health services in the UK. The elicitation of childhood trauma was not derived from the participants' AAls, but from a structured interview (the Cassel Baseline Questionnaire), independent from the AAI-derived unresolved/disorganized state of mind scoring. This procedure prevents the risk of conflation of the findings, reduces bias and increases the likelihood of obtaining more accurate self-reported childhood adversities, which are known to be underreported in the AAI (Hill, Byatt, \& Burnside, 2003). A further strength of this study consisted in its use of mediation analysis with bootstrap techniques using PROCESS, 
which does not rely on assumptions such as normally distributed indirect effects or sampling statistics, yielding a more powerful and accurate test of mediation compared to other approaches. Although most studies have reported on the AAl unresolved state of mind as a categorical variable, in recent years it has been increasingly used as on a continuous scale of severity, as it increases statistical power (Hesse, 2016; Hughes et al., 2004; Thomson \& Jaque, 2014). This is in line with more recent research which have investigated the usefulness of scoring the AAI on continuous scales to arrive at a dimensional understanding of attachment representations (Chiesa, Cirasola, Williams, Nassisi, \& Fonagy, 2016; Roisman, Fraley, \& Belsky, 2007).

Despite there being a broad theoretical framework linking lapses in reasoning and discourse confusion during the AAI with the $\mathrm{U} / \mathrm{d}$ classification, further research is required to evaluate what aspects of early experience lead to adult $\mathrm{U} / \mathrm{d}$ state of mind. Research in this field may lead to a better understanding and definition of the construct of $U / d$ state of mind, with important clinical implications. For instance, when treating patients with histories of loss and/or abuse the presence of $\mathrm{U} / \mathrm{d}$ state of mind characterized by lapses and discourse confusion may indicate the presence of ongoing and underlying dissociative processes. Treatment should then focus on the recovery and integration of traumatic memories with their associated affects and on the validation of patient's traumatic experiences. By targeting these aspects in therapy, the individual may move towards greater resolution of past loss and abusive experiences, which in turn may lead to better outcomes. The integration of trauma represents a platform for the development of affect tolerance, impulse control, integrated self-identity and defense organization (Niederland, 1965). 


\section{Conclusion}

The present study provides some support for the link between unresolved states of mind and PD pathology, and increases our understanding of the potential mechanisms underlying PD and its relationship to childhood traumatic experiences. However, since U-loss was found to be a significant mediator, while U-abuse was not, it is unclear whether unresolved state of mind is truly an independent risk factor for PD, which, due to the cross-sectional nature of the data, this study could not address. Future research using a prospective design, is required to investigate further the intricate links between childhood adversities, representational structures of early relational experiences and personality development. The study of areas of linkage between trauma, PD and Unresolved/disorganized attachment may have important clinical implications suggesting possible refinements of the targets for intervention.

\section{References}

American Psychiatric Association. (1995). Diagnostic and Statistical Manual for Mental Disorders (DSM-IV) (IV ed.). Washington: American Psychiatric Press.

Bailey, H. N., Moran, G., \& Pederson, D. R. (2007). Childhood maltreatment, complex trauma symptoms, and unresolved attachment in an at-risk sample of adolescent mothers. Attach Hum Dev, 9, 139-161.

Bakermans-Kranenburg, M. J., \& van IJzendoorn, M. H. (2009). The first 10,000 Adult Attachment Interviews: distributions of adult attachment representations in clinical and non-clinical groups. Attach Hum Dev, 11, 223-263.

Baron, R. M., \& Kenny, D. A. (1986). The moderator-mediator variable distinction in social psychological research: conceptual, strategic, and statistical considerations. J Pers Soc Psychol, 51, 1173-1182. 
Barone, L. (2003). Developmental protective and risk factors in borderline personality disorder: a study using the Adult Attachment Interview. Attach Hum Dev, 5, 64-77.

Barone, L., Fossati, A., \& Guiducci, V. (2011). Attachment mental states and inferred pathways of development in borderline personality disorder: a study using the Adult Attachment Interview. Attach Hum Dev, 13, 451-469.

Bender, D S, Dolan, R T, Skodol, A E, Sanislow, C A, Dyke, I R, McGlashan, T H, ... Gunderson, J G. (2001). Treatment utilization by patients with personality disorders. American Journal of Psychiatry, 158, 295-302.

Bifulco, A., Brown, G. W., \& Harris, T. O. (1994). Childhood experience of care and abuse (CECA): A retrospective interview measure. Journal of Child Psychology and Psychiatry, $35,1419-1435$.

Braun, K., \& Bock, J. (2011). The experience-dependent maturation of prefronto-limbic circuits and the origin of developmental psychopathology: implications for the pathogenesis and therapy of behavioural disorders. Dev Med Child Neurol, 53 Suppl 4, 14-18.

Brown, J., Cohen, P., Johnson, J. G., \& Smailes, E. M. (1999). Childhood abuse and neglect: specificity of effects on adolescent and young adult depression and suicidality. J Am Acad Child Adolesc Psychiatry, 38, 1490-1496.

Carlson, E. A. (1998). A prospective longitudinal study of attachment disorganization/disorientation. Child Dev, 69, 1107-1128.

Carr, C. P., Martins, C. M., Stingel, A. M., Lemgruber, V. B., \& Juruena, M. F. (2013). The role of early life stress in adult psychiatric disorders: a systematic review according to childhood trauma subtypes. J Nerv Ment Dis, 201, 1007-1020.

Chen, L. P., Murad, M. H., Paras, M. L., Colbenson, K. M., Sattler, A. L., Goranson, E. N., . . Zirakzadeh, A. (2010). Sexual abuse and lifetime diagnosis of psychiatric disorders: systematic review and meta-analysis. Mayo Clin Proc, 85, 618-629.

Chesin, M., Fertuck, E., Goodman, J., Lichenstein, S., \& Stanley, B. (2015). The interaction between rejection sensitivity and emotional maltreatment in borderline personality disorder. Psychopathology, 48, 31-35.

Chiesa, M. (2000). Hospital adjustment in personality disorder admitted to a therapeutic community milieu. British Journal of Medical Psychology, 73, 259-267. 
Chiesa, M, Cirasola, A, Williams, R, Nassisi, V, \& Fonagy, P. (2016). Categorical and dimensional approaches in the evaluation of the relationship between attachment and personality disorders: An empirical study. (in preparation).

Chiesa, M, \& Fonagy, P. (2014). Reflective function as a mediator between childhood adversity, personality disorder and symptom distress. Personality and Mental Health, 8, 52-66.

Chiesa, M., \& Fonagy, P. (2000). Cassel personality disorder study: methodology and treatment effects. British Journal of Psychiatry, 176, 485-491.

Cicchetti, D., Cummings, E.M., Greenberg, M.T., \& Marvin, R.S. (1990). An organizational perspective on attachment beyond infancy. In D. C. M.T.Greenberg \& E.M.Cummings (Eds.), Attachment in the Preschool Years: Theory, Research, and Intervention (pp. 349). Chicago: University of Chicago Press.

Crawford, T. N., Cohen, P. R., Chen, H., Anglin, D. M., \& Ehrensaft, M. (2009). Early maternal separation and the trajectory of borderline personality disorder symptoms. Dev Psychopathol, 21, 1013-1030.

Dakanalis, A., Timko, C. A., Carra, G., Clerici, M., Zanetti, M. A., Riva, G., \& Caccialanza, R. (2014). Testing the original and the extended dual-pathway model of lack of control over eating in adolescent girls. A two-year longitudinal study. Appetite, 82, 180-193.

Derogatis, L.R. (1983). SCL-90-R. Administration, scoring and procedures. Manual-II. Towson (MD): Clinical Psychometric Research.

Diamond, D., Levy, K. N., Clarkin, J. F., Fischer-Kern, M., Cain, N. M., Doering, S., . . Buchheim, A. (2014). Attachment and mentalization in female patients with comorbid narcissistic and borderline personality disorder. Personal Disord, 5, 428-433.

Dozier, M.K., Stowall-McColough, C., \& Albus, K.E. (2008). Attachment and psychopathology in adulthood. In J. Cassidy \& P. R. Shaver (Eds.), Handbook of Attachment Theory and Research (2nd ed., pp. 718-744). New York: Guilford Publications.

Duschinsky, R. (2015). The emergence of the disorganized/disoriented (D) attachment classification, 1979-1982. Hist Psychol, 18, 32-46.

Ekselius, L., Lindstrom, E., von Knorring, L., Bodlund, O., \& Kullgren, G. (1994). SCID II interviews and the SCID Screen questionnaire as diagnostic tools for personality disorders in DSM-III-R. Acta Psychiatr Scand, 90, 120-123. 
First, M B, Spitzer, RL, Gibbon, M, \& Williams, J B W. (1997). Structured Clinical Interview for the DSM-IV. Washington DC: American Psychiatric Press.

Fonagy, P, Luyten, P, Bateman, A, Gergerly, G, Strathearn, L., Target, M, \& Allison, E. (2010). Attachment and personality pathology. In J. L. Clarkin, P. Fonagy \& G. O. Gabbard (Eds.), Psychodynamic Psychotherapy for Personality Disorders: A Clinical Handbook. (1st edition ed., pp. 37-88). Washington DC.: American Psychiatric Publishing.

Fonagy, P, Luyten, P, \& Strathearn, L. (2011). Borderline personality disorder, mentalization, and the neurology of attachment. Infant Mental Health Journal, 32, 47-69.

Fonagy, P., Leigh, T., Steele, M., Steele, H., Kennedy, R., Mattoon, G., . . Gerber, A. (1996). The relation of attachment status, psychiatric classification, and response to psychotherapy. J Consult Clin Psychol, 64, 22-31.

Gabbard, G. O. (2005). Mind, brain, and personality disorders. Am J Psychiatry, 162, 648-655. George, C., Kaplan, N., \& Main, M. (1985). The Adult Attachment Interview, Department of Psychology, University of California at Berkeley.

Gunderson, J G, Shea, T M, Skodol, A E, McGlashan, T H, Morey, L C, Stout, R L, . . Keller, M B. (2000). The Collaborative Longitudinal Personality Disorder Study. I: Developments, Aims, Design, and Sample Characteristics. Journal of Personality Disorders, 14, 300315.

Hayes, A. F., \& Matthes, J. . (2009). Computational procedures for probing interactions in OLS and logistic regression: SPSS and SAS implementations. Behavior Research Methods, 41, 924-936.

Hesse, E. (2008). The adult attachment interview: Protocol, method of analysis, and empirical studies. In J. Cassidy \& P. R. Shaver (Eds.), Handbook of Attachment Theory and Research (2nd ed., pp. 552-558). New York: Guilford Publications.

Hesse, E. (2016). The Adult Attachment Interview Protocol, Method of Analysis, and Selected Empirical Studies: 1985-2015. In J. Cassidy \& P. R. Shaver (Eds.), Hanbook of Attachment (3rd ed., pp. 553-597). London: Guilford Press.

Hesse, E., \& van ljzendoorn, M. H. (1999). Propensities towards absorption are related to lapses in the monitoring of reasoning or discourse during the adult attachment interview. A preliminary investigation. Attach Hum Dev, 1, 67-91. 
Hill, J, Byatt, M, \& Burnside, E. (2003). Unresolved trauma and unresolved loss in childhood might have different implications for adult depression. Paper presented the Biennial Meeting of the Society for Research in Child Development: Trauma-related adult states of mind: Are they captured by the Adult Attachment Interview?, Tampa, FL.

Holmes, J. (2004). Disorganized attachment and borderline personality disorder: a clinical perspective. Attach Hum Dev, 6, 181-190.

Hughes, P., Turton, P., Hopper, E., McGauley, G. A., \& Fonagy, P. (2004). Factors associated with the unresolved classification of the Adult Attachment Interview in women who have suffered stillbirth. Dev Psychopathol, 16, 215-230.

Jacobsberg, L., Perry, S., \& Frances, A. (1995). Diagnostic agreement between the SCID-II screening questionnaire and the Personality Disorder Examination. J Pers Assess, 65, 428-433.

Johnson, J. G., Cohen, P., Kasen, S., Skodol, A. E., Hamagami, F., \& Brook, J. S. (2000). Agerelated change in personality disorder trait levels between early adolescence and adulthood: a community-based longitudinal investigation. Acta Psychiatr Scand, 102, 265-275.

Kraemer, H. C., Kiernan, M., Essex, M., \& Kupfer, D. J. (2008). How and why criteria defining moderators and mediators differ between the Baron \& Kenny and MacArthur approaches. Health Psychol, 27, S101-108.

Linehan, M.M., \& Heard, H.L. (1993). Commentary. In Z.V.Segal \& S.J.Blatt (Eds.), The Self in Emotional Distress: Cognitive and Psychodynamic Perspectives (pp. 161-370). New York and London: The Guilford Press.

Liotti, G. (1992). Disorganised/disorientated attachment in the aetiology of the dissociative disorders. Dissociation, 5, 196-204.

Lyons-Ruth, K. (1996). Attachment relationships among children with aggressive behavior problems: the role of disorganized early attachment patterns. J Consult Clin Psychol, $64,64-73$.

Lyons-Ruth, K., Yellin, C., Melnick, S., \& Atwood, G. (2003). Childhood experiences of trauma and loss have different relations to maternal Unresolved and Hostile-Helpless states of mind on the AAI. Attach Hum Dev, 5, 330-352; discussion 409-314. 
MacKinnon, D. P., Lockwood, C. M., Hoffman, J. M., West, S. G., \& Sheets, V. (2002). A comparison of methods to test mediation and other intervening variable effects. Psychol Methods, 7, 83-104.

Main, M., \& Goldwyn, R. (1991). Adult Attachment Classification System. Version 5. Berkley: University of California, .

Main, M., \& Hesse, E. (1990). Adult lack of resolution of attachment-related trauma related to infant disorganizedented behavior in the Ainsworth strange situation: Linking parental states of mind to infant bebavior in a stressful situation. In M. T. Greenberg, D. Cicchetti \& M. Cummings (Eds.), Attachment in the Preschool Years: Theory, Research and Intervention (pp. 339-426). Chicago: University of Chicago Press.

Main, M., Hesse, E. , \& Goldwyn, R. (2008). Studying differences in language usage in recounting attachment history: An introduction to the AAI. In H. Steele \& M. Steele (Eds.), Clinical applications of the Adult Attachment Interview. (pp. 31-68). New York: Guilford Press.

Main, M., \& Solomon, J. (1990). Procedures for identifying infants as disorganized/disoriented during the Ainsworth Strange Situation. In M. T. Greenberg, D. Cicchetti \& E. M. Cummings (Eds.), Attachment During the Preschool Years: Theory, Research and Intervention (pp. 121-160). Chicago: University of Chicago Press.

McCrory, E., De Brito, S. A., \& Viding, E. (2012). The link between child abuse and psychopathology: a review of neurobiological and genetic research. $J$ R Soc Med, 105, 151-156.

Meyer, B., Pilkonis, P. A., Proietti, J. M., Heape, C. L., \& Egan, M. (2001). Attachment styles and personality disorders as predictors of symptom course. J Pers Disord, 15, 371-389.

Niederland, W. G. (1965). The role of the ego in the recovery of early memories. Psychoanal Q, 34, 564-571.

Preacher, K. J., \& Hayes, A. F. (2008). Asymptotic and resampling strategies for assessing and comparing indirect effects in multiple mediator models. Behav Res Methods, 40, 879891.

Riggs, S. A., Paulson, A., Tunnell, E., Sahl, G., Atkison, H., \& Ross, C. A. (2007). Attachment, personality, and psychopathology among adult inpatients: self-reported romantic 
attachment style versus Adult Attachment Interview states of mind. Dev Psychopathol, 19, 263-291.

Roisman, G. I., Fraley, R. C., \& Belsky, J. (2007). A taxometric study of the Adult Attachment Interview. Dev Psychol, 43, 675-686.

Schore, A. N. (2009). Relational trauma and the developing right brain: an interface of psychoanalytic self psychology and neuroscience. Ann N Y Acad Sci, 1159, 189-203.

Skodol, A E, Gunderson, J G, McGlashan, T H, Dyck, I R, Stout, R L, Bender, D S, . . Oldham, J M. (2002). Functional impairment in patients with schizotypal, borderline, avoidant, or obsessive-compulsive personality disorder. American Journal of Psychiatry, 159, 276-283.

Soloff, P. H., Lynch, K. G., \& Kelly, T. M. (2002). Childhood abuse as a risk factor for suicidal behavior in borderline personality disorder. J Pers Disord, 16, 201-214.

Sroufe, L. A. (2005). Attachment and development: a prospective, longitudinal study from birth to adulthood. Attach Hum Dev, 7, 349-367.

Sroufe, L. A., Egeland, B, Carlson, E., \& Collins, W. A. (2005). Placing early attachment experiences in developmental context: The Minnesota Longitudinal Study. In K. E. Grossmann, K. Grossmann \& E. Waters (Eds.), Attachment from infancy to adulthood: The major longitudinal studies. (pp. 48-78). New York.: Guilford Press.

Steele, H. \& Steele M. (2008). Clinical applications of the Adult Attachment Interview. New York: Guilford Press.

Stovall-McClough, K. C., \& Cloitre, M. (2006). Unresolved attachment, PTSD, and dissociation in women with childhood abuse histories. J Consult Clin Psychol, 74, 219-228.

Thomson, P., \& Jaque, S. V. (2014). Unresolved mourning, supernatural beliefs and dissociation: a mediation analysis. Attach Hum Dev, 16, 499-514.

Torgersen, S. (2005). Behavioral genetics of personality. Curr Psychiatry Rep, 7, 51-56.

Tyrer, P, Reed, G M., \& Crawford, M J. (2015). Classification, assessment, prevalence, and effect of personality disorder. The Lancet, 385, 717-726.

Tyrer, P. (2009). Recurrence of self-harm \& severity of personality disorder. Acta Psychiatr Scand, 120, 82; author reply 82-83. 
Van ljzendoorn, M. H., \& Bakermans-Kranenburg, M. J. (2006). DRD4 7-repeat polymorphism moderates the association between maternal unresolved loss or trauma and infant disorganization. Attach Hum Dev, 8, 291-307.

Zanarini, M. C. (2000). Childhood experiences associated with the development of borderline personality disorder. Psychiatr Clin North Am, 23, 89-101. 
Table 1 Socio-demographic, severity characteristics and childhood adversity variables in the personality disorder (PD) and non-PD samples

\begin{tabular}{|c|c|c|c|}
\hline & PD & Non-PD & Sig \\
\hline Age mean (SD) & $31.34(9.08)$ & $32.76(5.24)$ & $t_{(243)}=1.50$ \\
\hline Female $\mathbf{N}(\%)$ & $85(68.5 \%)$ & $83(68.6 \%)$ & $\chi^{2}(1)=0.00$ \\
\hline GSI mean (SD) & $58.29(10.04)$ & $40.67(8.62)$ & $t_{(243)}=-14.73 * * *$ \\
\hline Loss N (\%) & $71(57.3 \%)$ & $14(11.6 \%)$ & $\chi^{2}(1)=56.42 * * *$ \\
\hline Sexual abuse $\mathbf{N}(\%)$ & $62(50 \%)$ & $6(5 \%)$ & $\chi^{2}(1)=61.96^{* * *}$ \\
\hline Physical abuse $\mathbf{N}(\%)$ & $54(43.5 \%)$ & $8(6.6 \%)$ & $\chi^{2}(1)=44.20 * * *$ \\
\hline \multicolumn{4}{|l|}{ 4way AAI Main categories $\mathbf{N}(\%)$} \\
\hline Secure & $12(14.6 \%)$ & $70(85.4 \%)$ & $\chi^{2}(1)=63.83^{* * *}$ \\
\hline Dismissing & $28(53.8 \%)$ & $24(46.2 \%)$ & $\chi^{2}(1)=0.28$ \\
\hline Preoccupied & $15(48.4 \%)$ & $16(51.6 \%)$ & $\chi^{2}(1)=0.70$ \\
\hline Unresolved/Disorganized & $69(86.3 \%)$ & $11(13.8 \%)$ & $\chi^{2}(1)=60.36^{* * *}$ \\
\hline \multicolumn{4}{|l|}{ Unresolved N (\%) } \\
\hline Unresolved abuse & $43(34.7 \%)$ & $9(17.3 \%)$ & $\chi^{2}(1)=27.17^{* * *}$ \\
\hline Unresolved loss & $34(27 \%)$ & $2(1.7 \%)$ & $\chi^{2}(1)=32.44^{* * *}$ \\
\hline
\end{tabular}

$* * * p>0.001$ 
Table 2 logistic regression analyses with forced entry with personality disorder (PD) and PD categories as outcome variables and adversity variables (loss, sexual abuse and physical abuse) as independent variables

\begin{tabular}{|c|c|c|c|}
\hline Outcome variables & B [SE] & $\mathbf{P}$ & Odds ratio $[95 \% \mathrm{Cl}]$ \\
\hline \multicolumn{4}{|l|}{ Adversity variables } \\
\hline \multicolumn{4}{|l|}{ PD } \\
\hline Loss & $2.04[0.38]$ & $<0.001$ & $7.65[3.60,16.26]$ \\
\hline Sexual abuse & $2.44[0.50]$ & $<0.001$ & $11.44[4.32,30.21]$ \\
\hline Physical abuse & $1.95[0.47]$ & $<0.001$ & $6.99[2.79,17.49]$ \\
\hline \multicolumn{4}{|c|}{$\mathrm{R}^{2}=.54$ (Nagelkerke); Model $\chi^{2}(3)=128.32, p<0.0001$} \\
\hline \multicolumn{4}{|l|}{ Paranoid PD } \\
\hline Loss & $-0.23[0.38]$ & 0.545 & $0.78[0.38,1.67]$ \\
\hline Sexual abuse & $1.77[0.38]$ & $<0.001$ & $5.89[2.80,12.38]$ \\
\hline Physical abuse & $0.86[0.37]$ & $<0.03$ & $2.37[1.14,4.94]$ \\
\hline \multicolumn{4}{|c|}{$\mathrm{R}^{2}=.30$ (Nagelkerke); Model $\chi_{(3)}^{2}=58.62, p<0.0001$} \\
\hline \multicolumn{4}{|l|}{ Borderline PD } \\
\hline Loss & $0.82[0.32]$ & $<0.01$ & $2.28[1.20,4.31]$ \\
\hline Sexual abuse & $1.33[0.34]$ & $<0.001$ & $3.78[1.95,7.32]$ \\
\hline Physical abuse & $0.63[.34]$ & 0.067 & $1.89[0.95,3.72]$ \\
\hline \multicolumn{4}{|c|}{$\mathrm{R}^{2}=.23$ (Nagelkerke); Model $\chi^{2}(3)=42.23, p<0.0001$} \\
\hline \multicolumn{4}{|l|}{ Avoidant PD } \\
\hline Loss & $1.23[0.34]$ & $<0.001$ & $3.41[1.74,6.67]$ \\
\hline Sexual abuse & $1.53[0.35]$ & $<0.001$ & $4.66[2.34,9.28]$ \\
\hline Physical abuse & $1.19[0.36]$ & $<0.001$ & $3.29[1.63,6.64]$ \\
\hline \multicolumn{4}{|c|}{$\mathrm{R}^{2}=.36$ (Nagelkerke); Model $\chi^{2}(3)=70.33 p<0.0001$} \\
\hline
\end{tabular}


Table 3. Linear regression with number of PD diagnosis and GSI mean score as outcome variables, with $95 \%$ bias corrected and accelerated confidence intervals $(\mathrm{Cl})$. $\mathrm{Cl}$ and Standard error (SE) based on 1000 bootstrap samples

\begin{tabular}{lccccc}
\hline & B & $95 \% \mathbf{C l}$ & SE B & $\boldsymbol{\beta}$ & $\mathbf{P}$ \\
\hline DV: Number of PD & & & & & \\
\hline Constant & 0.65 & $0.39-0.92$ & 0.13 & & 0.001 \\
All losses & 1.22 & $0.58-1.88$ & 0.33 & 0.23 & 0.001 \\
Sexual abuse & 2.04 & $1.23-2.87$ & 0.40 & 0.35 & 0.001 \\
Physical abuse & 1.47 & $0.65-2.27$ & 0.41 & 0.25 & 0.002 \\
\hline DV: GSI & & & & & \\
\hline Constant & 43.39 & $41.80-45.21$ & 0.90 & & 0.001 \\
All losses & 4.14 & $0.90-7.40$ & 1.63 & 0.15 & 0.018 \\
Sexual abuse & 9.23 & $6.34-12.22$ & 1.51 & 0.32 & 0.001 \\
Physical abuse & 8.67 & $5.34-11.76$ & 1.63 & 0.29 & 0.001 \\
\hline
\end{tabular}


Figure 1. Mediation of relationships between childhood adversity and current PD diagnosis through U-overall. Unstandardized coefficients are reported for each path

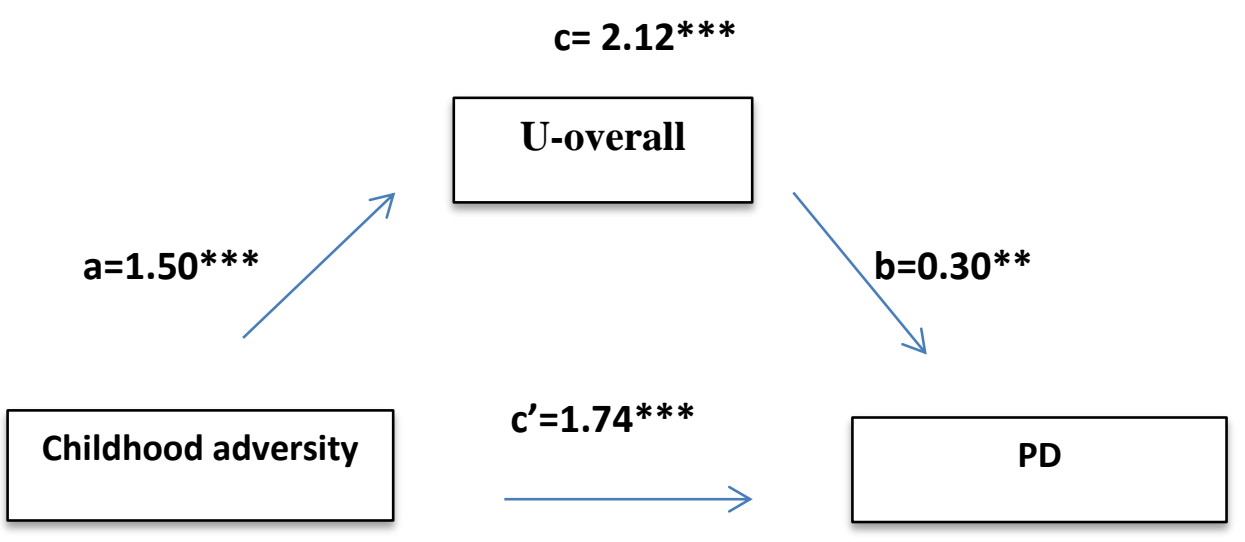

$* * \mathrm{p}<0.01 * * * \mathrm{p}<0.001$ 
Figure 2. Mediation of relationships between childhood loss and current PD diagnosis through U-loss. Unstandardized coefficients are reported for each path

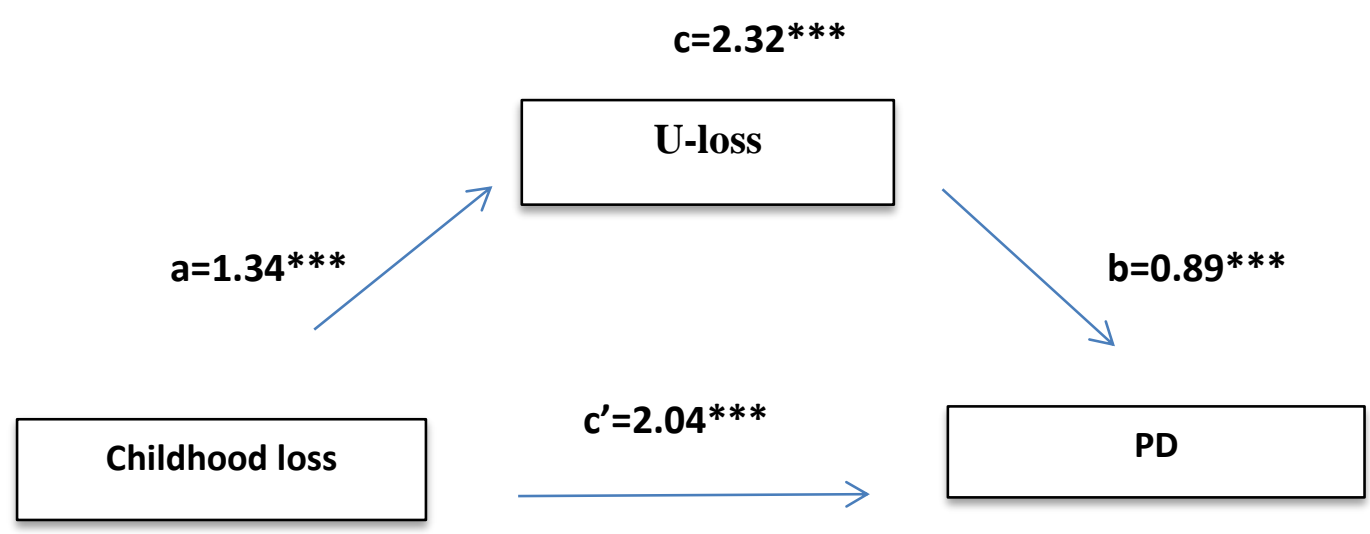

$* * * p<0.001$ 